\title{
Electrical Coupling and Synchronized Subthreshold Oscillations in the Inferior Olive of the Rhesus Macaque
}

\author{
Josef Turecek, ${ }^{1,2}$ Victor Z. Han, ${ }^{2}$ Verginia C. Cuzon Carlson, ${ }^{3}$ Kathleen A. Grant, ${ }^{3,4}$ and John P. Welsh ${ }^{2,5}$ \\ ${ }^{1}$ Department of Neurobiology, Harvard Medical School, Boston, Massachusetts $02115,{ }^{2}$ Center for Integrative Brain Research, Seattle Children's Research \\ Institute, Seattle, Washington 98101, ${ }^{3}$ Division of Neuroscience, Oregon National Primate Research Center, Beaverton, Oregon 97006, ${ }^{4}$ Department of \\ Behavioral Neuroscience, Oregon Health \& Science University, Portland, Oregon 97239, and 5Department of Pediatrics, University of Washington, Seattle, \\ Washington 98195
}

Inferior olive (I0) neurons are critical for motor coordination and exhibit oscillations in membrane potential that are subthreshold for spiking. The prevalence, coherence, and continuity of those subthreshold oscillations (STOs) depend upon resonant interactions between neighboring neurons supported by electrical coupling. Many studies of the olivocerebellar system in rodents, in which STOs were related to tremor, whisking, and licking, fueled a debate over whether IO STOs were relevant for primates whose repertoire of movement is generally less periodic. The debate was never well informed due to the lack of a direct examination of the physiological properties of primate IO neurons. Here, we obtained dual patch-clamp recordings of neighboring IO neurons from young adult macaques in brainstem slices and compared them to identical recordings from rats. Macaque IO neurons exhibited an equivalent prevalence of continuous STOs as rats ( $45 \mathrm{vs} 54 \%$, respectively). However, macaque STOs were slower $(1-4 \mathrm{~Hz})$ and did not overlap with the dominant $4-9 \mathrm{~Hz}$ frequency of rats. The slower STO frequency of macaques was at least partially due to a prolonged membrane time constant and increased membrane capacitance that could be attributed to stronger electrical coupling and greater total dendritic length. The presence of synchronized STOs in the IO of adult macaques, coincident with strong and prevalent electrical coupling, answers a fundamental outstanding question in cerebellar neuroscience and is consistent with a prominent role for synchronized oscillation in primate sensory-motor control.

Key words: electrical synapse; inferior olive; oscillation; primate; synchrony

\section{Significance Statement}

It was debated whether inferior olive (IO) neurons of primates behave as synchronized oscillators as was found for rodents using intracellular, optical, and multielectrode recordings. An inability to resolve this issue using single-Purkinje cell extracellular recordings in monkeys limited our understanding of timing mechanisms in the primate brain. Using dual whole-cell recordings from the IO of young adult rhesus macaques in acutely prepared brainstem slices, our work demonstrates that pairs of primate IO neurons show synchronized oscillations in membrane potential. The findings have strong mechanistic and translational relevance, as IO activation has been implicated in humans' perceptual timing of sensory events and motricity.

\section{Introduction}

The inferior olive (IO) is essential for motor coordination and gives rise to climbing fibers (CFs) that synapse upon Purkinje cells (PCs) in cerebellar cortex (Szentágothai and Rajkovits, 1959; Eccles et al., 1964). The only synaptic communication between

Received Dec. 16, 2015; revised April 13, 2016; accepted May 5, 2016.

Author contributions: J.T. and J.P.W. designed research; J.T. and V.Z.H. performed research; J.T., V.C.C.C., and K.A.G. contributed unpublished reagents/analytic tools; J.T. and J.P.W. analyzed data; J.T. and J.P.W. wrote the paper.

This work was supported by United States Public Health Service Grants R21 NS079110 (J.P.W.), R01 NS31224-20 (J.P.W.), R24 AA019431 (K.A.G.), and U01 AA013510 (K.A.G.).

The authors declare no competing financial interests.

Correspondence should be addressed to Dr John P. Welsh, Seattle Children's Research Institute, 1900 9th Avenue, Seattle, WA 98101. E-mail: john.welsh@seattlechildrens.org.

DOI:10.1523/JNEUROSCI.4495-15.2016

Copyright $\odot 2016$ the authors $\quad 0270-6474 / 16 / 366497-06 \$ 15.00 / 0$
IO neurons is through electrical coupling (Llinás et al., 1974; Sotelo et al., 1974), which promotes and synchronizes oscillations in membrane potential that are subthreshold for spiking (Llinás and Yarom, 1986; Long et al., 2002; De Zeeuw et al., 2003; Placantonakis et al., 2006). The strength of subthreshold oscillations (STOs) is modulated by GABAergic and glutamatergic inputs that regulate electrical coupling by shunting junctional current or second-messenger action (Lefler et al., 2014; Mathy et al., 2014, Turecek et al., 2014). IO STOs are not an artifact of slicing as they occur in vivo under anesthesia (Chorev et al., 2007; Khosrovani et al., 2007; Bazzigaluppi et al., 2012b). Given their persistent rhythmicity, IO STOs have been a source of intrigue for decades and have been hypothesized to convey motor timing to cerebellar cortex or drive cerebellar plasticity via CFs (Llinás, 1991; Welsh and Llinás, 1997; Jacobson et al., 2008; Mathy et al., 2009). 
Although the synaptic effects of IO neurons on PCs have been studied in many species, IO neurons themselves have been characterized almost exclusively in rodents. That has prevented understanding whether principles of motor control derived from the properties of STOs generalize to humans. Indeed, PC CF responses in the range of STO frequencies were found to be correlated to licking (Welsh et al., 1995) and whisker (Lang et al., 2006) behaviors in rats. However, oscillations in PC CF responses were observed only in the summed activity of dozens of simultaneously recorded PCs during movement, indicating that IO spike output was entrained by a rhythmic process distributed over a network, a signature of an underlying STO (Welsh et al., 1995). As theories of motor control were formulated based on converging in vitro and in vivo studies (Llinás, 1991; Welsh and Llinás, 1997; Jacobson et al., 2008), it was counter-argued that rhythmic IO activity was a consequence of the unique periodicity of rodent behavior and irrelevant for primates (Thach, 2002). The counterargument was supported by experiments in which CF responses of single PCs were not found to be rhythmic during primates' arm movements (Keating and Thach, 1995), casting doubt on the proposal that STO entrainment of spiking was evolutionarily important, ultimately concluding that IO STOs were nonphysiological (Hakimian et al., 2008).

It is noteworthy that IO neurons from cynomolgus macaques have many of the ionic conductances found in rodents (Welsh et al., 2011) and that gap junctions exist within the primate IO (Rutherford and Gwyn, 1980). However, whether the primate IO generates synchronized STOs is unknown. Here, we used dual whole-cell recordings to examine the properties of neuron pairs within the rhesus macaque IO maintained alive in vitro and compared them to identical recordings from rats. An absence of electrical coupling and STOs in the macaque IO would argue against a role for IO rhythms in primates. Conversely, the presence of synchronized STOs reinforced by strong electrical coupling in the macaque IO would support a conserved function across species. Our findings indicate the latter.

\section{Materials and Methods}

Animals. Primate procedures were approved by the Oregon National Primate Research Center Animal Care and Use Committee and performed according to the National Institutes of Health Guidelines for the Care and Use of Mammals in Neuroscience and Behavioral Research.

Electrophysiology. P21-P50 rats of either sex $(n=24)$ were anesthetized and transcardially perfused or decapitated. The brainstem was sectioned parasagittally $(250 \mu \mathrm{m})$ in chilled high-sucrose ACSF made from the following (in mM): 252 sucrose, $2 \mathrm{KCl}, 1.25 \mathrm{NaH}_{2} \mathrm{PO}_{4}, 24 \mathrm{NaHCO}_{3}$, $2.6 \mathrm{CaCl}_{2}, 1.6 \mathrm{MgSO}_{4} \cdot 7 \mathrm{H}_{2} \mathrm{O}, 10$ glucose, oxygenated with $95 \% \mathrm{O}_{2} / 5 \%$ $\mathrm{CO}_{2}, \mathrm{pH}$ 7.4. Young adult (78-86 month) rhesus macaques $(n=5 ; 4$ male, 1 female) born and raised at the Oregon National Primate Research Center were transcardially perfused during anesthesia before the brain was removed and dissected (Welsh et al., 2011). All other brain tissue and other organs were prepared for use by other experimenters. Brainstem slices were incubated in $32^{\circ}-34^{\circ} \mathrm{C}$ sucrose ACSF $(1 \mathrm{~h})$, then replaced with ACSF containing the following (in mM): $124 \mathrm{NaCl}, 2 \mathrm{KCl}, 1.25 \mathrm{NaH}_{2} \mathrm{PO}_{4}, 24$ $\mathrm{NaHCO}_{3}, 2 \mathrm{CaCl}_{2}, 2 \mathrm{MgSO}_{4} \cdot 7 \mathrm{H}_{2} \mathrm{O}, 10$ glucose, oxygenated with $95 \%$ $\mathrm{O}_{2} / 5 \% \mathrm{CO}_{2}, \mathrm{pH} 7.4$, and incubated $(1 \mathrm{~h})$. The quality of macaque and rat brainstem slices was comparable. Recordings $\left(32^{\circ}-34^{\circ} \mathrm{C}\right)$ were performed in the principal or medial accessory subnucleus, excepting the dorsal cap. Electrodes (3-6 M $\Omega$ ) were filled with the following (in mM): $130 \mathrm{~K}$-gluconate, 5 EGTA, $10 \mathrm{HEPES}, 3 \mathrm{KCl}, 2 \mathrm{MgCl}_{2}, 1 \mathrm{Na}_{2} \mathrm{ATP}_{4}, 5 \mathrm{Na}_{2}$ phosphocreatine, and $0.4 \mathrm{Na}_{2}$ GTP. Recordings were collected using a Multiclamp 700B amplifier and Digidata 1440A digitizer (Molecular Devices).

Analysis. Electrical coupling strength was quantified in current-clamp to derive the coupling coefficient (CC; Devor and Yarom, 2002; Hoge et al., 2011). Hyperpolarizing current injections (300-500 pA, 200-300 $\mathrm{ms}$ ) were adjusted to elicit $20-40 \mathrm{mV}$ deflections. The $\mathrm{CC}$ was measured from averaged traces $(25-50$ trials, $0.1 \mathrm{~Hz})$ as the ratio of voltage deflection minima during the first $100 \mathrm{~ms}$ of current injection. Cells were considered electrically coupled if the post-junctional cell exhibited an identifiable voltage deflection matching the time course of the injected cell. CCs were determined only for neurons in which STOs were absent or intermittent. The symmetry coefficient was defined as $\mathrm{CC}_{\mathrm{A}-\mathrm{B}} / \mathrm{CC}_{\mathrm{B}-\mathrm{A}}$, where $\mathrm{CC}_{\mathrm{A}-\mathrm{B}}<\mathrm{CC}_{\mathrm{B}-\mathrm{A}}$. Input resistance and membrane time constants were measured using $\pm 50-100 \mathrm{pA}$ injections that did not elicit active conductances. The time constant was measured by fitting a single exponential to the resulting voltage deflection. Under voltage-clamp, the membrane capacitance was measured by integrating capacitive transients elicited by $5 \mathrm{mV}$ voltage steps from $-70 \mathrm{mV}$.

Analysis of STOs was restricted to neurons that exhibited generalized periodic waveforms. STO frequency was measured as the average time between maxima of five cycles. STO amplitude was measured as the average peak to trough voltage difference of five cycles. Phase offsets were measured as the time lag between the first peak of crosscorrelogram between paired recordings during STOs.

Anatomical reconstruction. Cells were filled with neurobiotin and processed as described previously (Turecek et al., 2014). Imaging was performed with a Zeiss LSM-710 confocal microscope (40-100 optical sections, 1-2 $\mu \mathrm{m}$ spacing, fixed laser intensity). Only cells with "curly" morphology (Devor and Yarom, 2002) were analyzed. Dendritic trees were reconstructed by hand using the simple neurite tracer tool of ImageJ (Longair et al., 2011). Wire diagrams were analyzed using custom MATLAB scripts.

Statistics. Normally distributed (naturally or by log-transform) data were analyzed using unpaired, two-tailed $t$ test. Non-normally distributed data were analyzed using ANOVA on the ranks. Data are presented as mean \pm 1 SEM and significance was set at $p<0.05$.

\section{Results}

The dataset consisted of whole-cell recordings of 134 rat IO neurons and 49 macaque IO neurons. Among the dataset, 62 paired recordings were from rats and 20 paired recordings were from macaques. Recordings from rats were taken from a subset of previously published work (Turecek et al., 2014).

\section{STOs are slower in the primate IO in vitro}

The immediately notable difference was that the frequency of STOs in the macaque IO was slower than rats. Macaque IO neurons oscillated at $1.8 \pm 0.2 \mathrm{~Hz}$ (Fig. $1 A, B$ ), significantly slower than the $4.7 \pm 0.2 \mathrm{~Hz}$ average for rat (Fig. $1 A, B ; t_{(92)}=7.6, p<$ $0.001)$. The mean STO amplitude was not significantly different $\left(6.0 \pm 1.3 \mathrm{mV}\right.$ macaque vs $6.7 \pm 0.6 \mathrm{mV}$ rat; Fig. $1 B ; t_{(92)}=-0.56$, $p=0.56)$. The occurrence of spontaneous STOs was comparable (22/49 cells macaque vs 72/134 rat). All pairs oscillated synchronously across a $0-100 \mu \mathrm{m}$ range of intersomatic distance $(n=36$ rat, $n=11$ macaque), with only modest phase differences (Fig. $1 F$ ).

STOs have been classified into subtypes based on waveform (Khosrovani et al., 2007). "Sinusoidal STOs" (sin-STOs) have a sinusoidal shape and range 3-10 Hz in rodents (Fig. 1A), whereas "low-threshold STOs" (L-STOs) have a saw-tooth shape (Fig. 1C). A small fraction of L-STOs also appear as periodic lowthreshold bursts of membrane depolarization (Fig. 1D). In our dataset, the percentage of sin-STOs for rat and macaque was $64 \%$ and $73 \%$, respectively, and the percentage of L-STOs was 36\% and $27 \%$, respectively. The frequency difference between sinSTOs and L-STOs followed the rodent trend of L-STOs being slower with macaque sin- and L-STOs averaging $2.1 \pm 0.3 \mathrm{~Hz}$ and $0.6 \pm 0.4 \mathrm{~Hz}$, respectively. In sum, the recordings indicated that STOs in the macaque IO were as prevalent as in rat, showed identical waveform characteristics and subgrouping, and were 

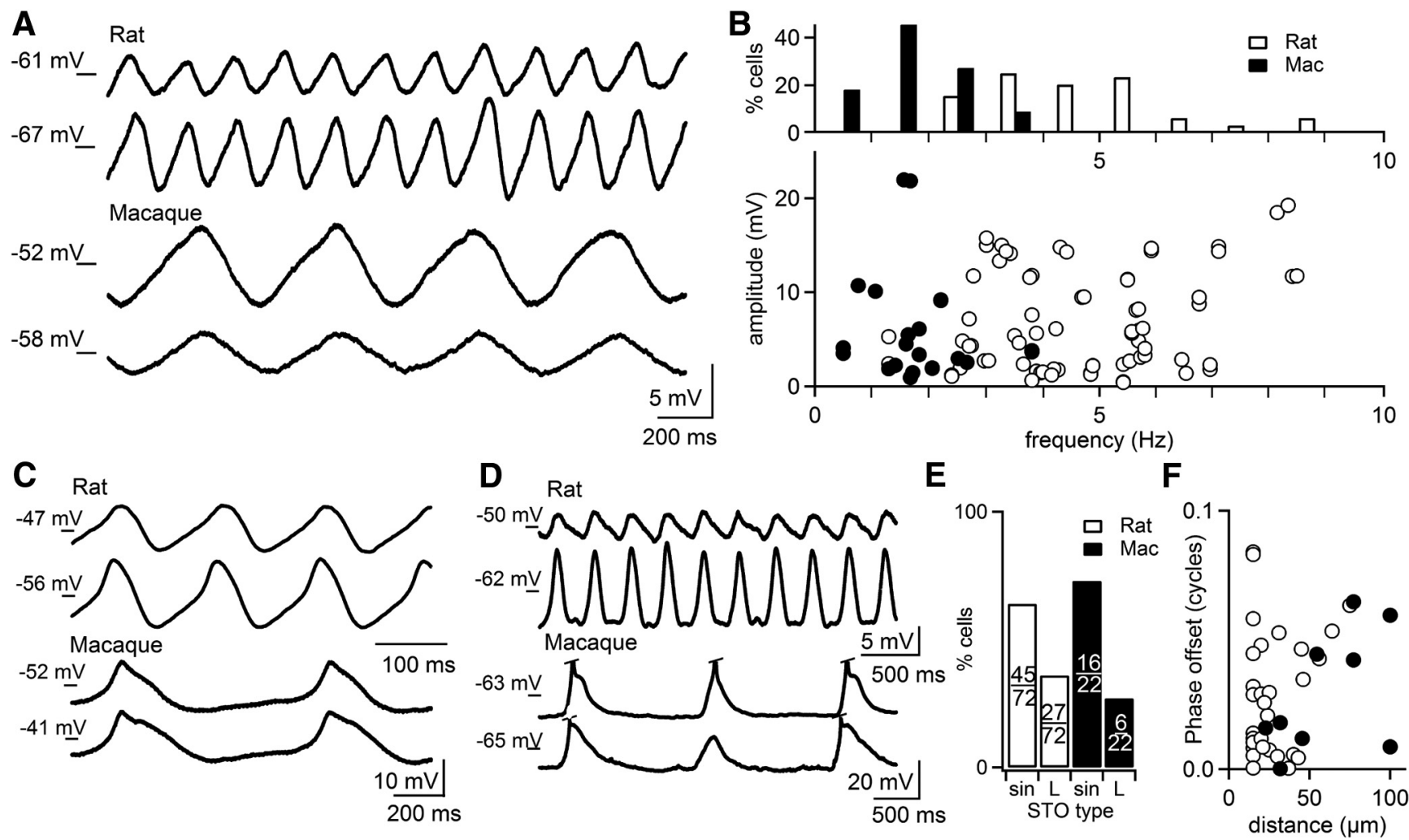

Figure 1. Synchronized STOs in the primate 10 are slower than in rats. $\boldsymbol{A}$, Example pair of rat (top; $5.8 \mathrm{~Hz}$ ) and macaque (bottom; $1.8 \mathrm{~Hz}) 10$ neurons exhibiting synchronized sin-STOs. $\boldsymbol{B}$, STO frequency distribution for macaque and rat (top) and plot of STO amplitude versus STO frequency (bottom). Each point is one cell. C, Example of synchronized, saw-tooth-shaped L-STOs in rat (6.9 Hz) and macaque $(1.2 \mathrm{~Hz})$ pairs. $\boldsymbol{D}$, Examples of synchronized bursting L-STOs in rat $(3.2 \mathrm{~Hz})$ and macaque $(0.76 \mathrm{~Hz})$. $\boldsymbol{E}$, Fraction of sin-STOs and L-STOs in rats and macaques. $\boldsymbol{F}$, STO phase offset over intersomatic distances $0-100 \mu \mathrm{m}$.

phase-locked across intersomatic distance up to $100 \mu \mathrm{m}$. Yet, STOs were consistently slower in the macaque, with most oscillating at $\sim 2 \mathrm{~Hz}$.

\section{Primate IO neurons are more capacitive}

To determine the basis of the frequency differences between primate and rodent STOs, we measured the electrical properties for quiescent or intermittently oscillating rat $(n=86)$ and macaque $(n=42)$ IO neurons. Every macaque IO neuron exhibited active membrane properties of rodent IO neurons (Fig. $2 A$ ). We found significantly slower time course of subthreshold voltage deflections in response to hyperpolarizing current injection and in the timing of rebound spiking in macaques (Fig. $2 B$ ). In addition, there were significant differences in their passive membrane properties (Fig. $2 \mathrm{C}$ ). Macaque IO neurons displayed higher input resistances $(83.3 \pm 2.7 \mathrm{M} \Omega$, rat vs $107.3 \pm 4.8 \mathrm{M} \Omega$, macaque; $\left.t_{(126)}=-4.6, p<0.001\right)$, and slower membrane time constants $(5.3 \pm 0.2 \mathrm{~ms}$, rat vs $10.0 \pm 0.7 \mathrm{~ms}$, macaque; $\left.t_{(126)}=-7.6, p<0.001\right)$. From those measurements, we estimated the capacitance using the formula for passive membranes and found that macaque IO neurons were $42 \%$ more capacitive than rat IO neurons $(66.9 \pm 2.3 \mathrm{pF}$, rat vs $94.7 \pm 5.5 \mathrm{pF}$, macaque; Fig. $2 C$; $\left.t_{(126)}=4.1, p<0.001\right)$. Similar results were found under voltageclamp (46.8 $\pm 1.6 \mathrm{pF}$, rat vs $98.3 \pm 6.5 \mathrm{pF}$, macaque; $t_{(126)}=-9.7$, $p<0.001)$.

Primate IO neurons exhibit stronger and more prevalent apparent electrical coupling

One influence on the membrane time constant of IO neurons is the presence and strength of electrical coupling which adds a capacitive load to the recorded neuron. We compared electrical coupling between macaque and rat IO neurons. Because the strength and prevalence of electrical coupling varies as a function of distance (Devor and Yarom, 2002; Turecek et al., 2014), we analyzed pairs separated by $40-80 \mu \mathrm{m}$ for which we had comparable number of samples in rats $(n=15)$ and macaques $(n=11)$. On average, the strength of the apparent electrical coupling was $86 \%$ greater in macaque (Fig. $3 A$ ). Whereas rat pairs had an average CC of $0.7 \pm 0.1 \%$, macaque pairs had an average CC of $1.3 \pm 0.2 \%\left(t_{(35)}=-3.5, p=0.001\right.$; Fig. $\left.3 B\right)$. The prevalence of electrical coupling was also greater in the primate with $100 \%$ of pairs in the macaque coupled between 40 and $80 \mu \mathrm{m}$ intersomatic distance, whereas only $50 \%$ of rat pairs showed detectable coupling over that distance $\left(\chi_{(1)}^{2}=13.1, p<0.001\right.$; Fig. $\left.3 C\right)$. There was no major difference in coupling symmetry between species (Fig. 3D). The analyses indicated that voltage deflections in macaque IO neurons are transmitted more effectively to the surrounding ensemble of IO neurons, which should in turn increase the capacitive load onto macaque IO neurons and slow STOs.

\section{Primate IO neurons have longer dendrites and broader dendritic trees}

A second influence on the membrane time constant is dendritic morphology which can affect the area of plasmalemma membrane. We reconstructed neurobiotin-filled IO neurons in both species to determine whether there were morphological differences (Fig. $4 A, B$ ). The length of the dendrites and breadth of the dendritic tree were significantly greater in macaques as determined by three measures. First, total dendritic length was 53\% greater in macaques $(4343 \pm 284 \mu \mathrm{m}$, rat vs $6663 \pm 329 \mu \mathrm{m}$, 
A

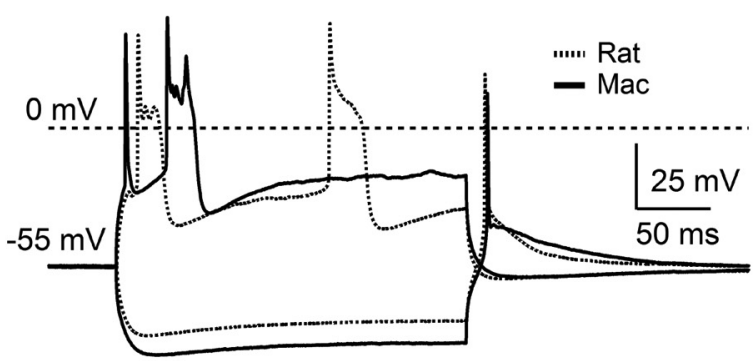

\section{B}
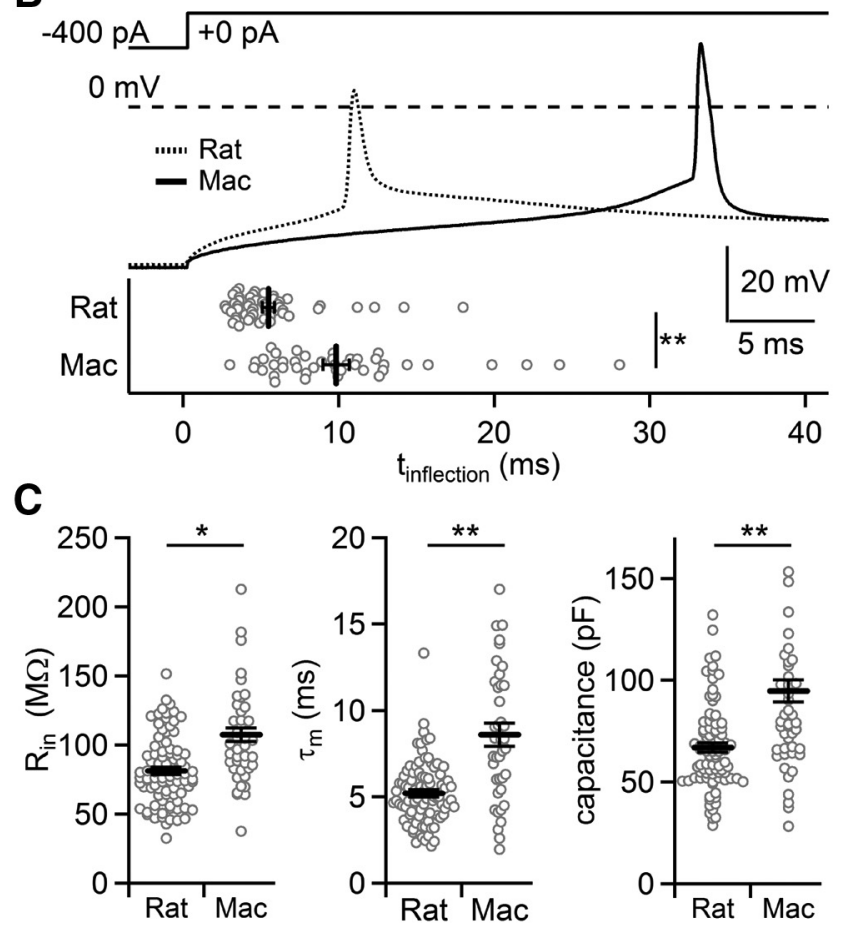

Figure 2. The membrane time constant of primate 10 neurons is slower than in rats. $\boldsymbol{A}$, Current injections of $-400 /+500 \mathrm{pA}$ in example rat and macaque 10 neurons. $\boldsymbol{B}$, Rebound spikes from rat and macaque 10 neurons (top), raw data, and average inflection time following release from hyperpolarization (bottom). C, Raw data, average membrane time constant, input resistance, and membrane capacitance. ${ }^{*} p<0.01,{ }^{* *} p<0.001$. Error bars show \pm 1 SEM.

macaque; Fig. 4C). Second, we determined the summed length of the dendrites within 5- $\mu \mathrm{m}$-radius steps from the soma (Fig. $4 D$ ). Dendritic segments $>80 \mu \mathrm{m}$ from the soma contributed $31 \%$ of total dendritic length for macaque $(2052 \pm 499 \mu \mathrm{m})$ compared with only $18 \%$ for rat $\left(792 \pm 169 \mu \mathrm{m} ; t_{(8)}=2.4, p=0.04\right)$. Third, we determined the total dendrite length along defined distances within each dendrite, or the electrotonic distance (Fig. 4E). For macaque, there was a greater total length of dendritic segments closer than $200 \mu \mathrm{m}$ from the soma $(5310 \pm 400 \mu \mathrm{m}$, macaque vs $3200 \pm 230 \mu \mathrm{m}$, rat; $\left.t_{(8)}=4.6, p=0.002\right)$, consistent with the larger membrane time constant in macaque IO neurons due to greater perisomatic membrane area.

\section{Discussion}

Our findings demonstrate that neurons of the primate IO are more prevalently and strongly electrically coupled than in the rat and exhibit synchronized STOs having stable phase over anatomical distance. The stronger electrical coupling combined with greater dendritic length in macaque IO neurons contributes to significantly larger capacitance. Those factors would be expected to contribute to the significantly slower STO in macaque IO neurons. The findings of synchronous STOs and robust electrical coupling in the IO of macaques provide the first indication that operating principles of the olivocerebellar system established for rodents generalize to primates.

The work presented here comes with several caveats. First, we compared young adult macaques with juvenile rats. However, the STOs we recorded in juvenile rats were similar to those recorded in adult rodents in vivo and in vitro (Chorev et al., 2007; Khosrovani et al., 2007; Bazzigaluppi et al., 2012b) and the morphology presented here is similar to reports using adult mice (Khosrovani et al., 2007). Second, it remains to be shown that macaque IO neurons in vivo oscillate more slowly than rodents as found in vitro, which will require further investigation.

The frequency of STOs can be determined by several factors, as demonstrated by experimental and computational results (Manor et al., 1997, De Gruijl et al., 2012), and it is unclear the relative influence each of them has to slow STOs in macaques. In simple two-compartment models of IO neurons, STOs are generated by the interaction of somatic T-type calcium and dendritic leak currents. The relative density of those currents and the properties of electrically coupled input are both strong determinants of STO frequency. The capacitance mediated by dendrites and electrical coupling also plays a role in determining STO frequency, as temporal changes in membrane potential are directly proportional to both capacitance and the magnitude of the underlying currents. Although macaque IO neurons are more capacitive and are more strongly electrically coupled than in rats, it is likely that an interplay of multiple active and passive membrane properties contributes to slower STO frequencies in macaques. For example, increased capacitance may require larger somatic T-type current density to successfully drive STOs.

On a systems level, it has been controversial whether the primate IO operates through synchronized oscillatory activity due to two reasons. Foremost, the oscillatory and electrical coupling properties of primate IO neurons were never directly measured. Second, the properties of primate IO neurons were inferred based on in vivo experiments of CF responses, which were performed differently than in rodents. Although no oscillatory activity in $\mathrm{CF}$ responses of single PCs was detected during limb movement in monkeys (Keating and Thach, 1995), CF responses summed over many PCs revealed population oscillations during oro-facial movement in rats (Welsh et al., 1995; Lang et al., 2006). Arguments against the generality of the rodent findings were that single PC recordings summed over sequential movement trials should have revealed an oscillatory tendency in CF responses (Keating and Thach, 1995) and that the lack of an olivocerebellar oscillation in single PCs indicated that rhythmic rodent behaviors did not represent primate movement (Thach, 2002). The counterargument was that the effect of synchronized STOs in the IO on spike timing was probabilistic, more readily observable over a distributed network, and emphasized that significant reorganization of electrical coupling occurs in real-time during movement to affect STO phase, further increasing the difficulty of revealing a fixed oscillation in the CF responses of single PCs (Welsh et al., 1995; Welsh and Llinás, 1997).

Our finding of synchronized STOs in the primate IO resolves the most fundamental issue by demonstrating that primate IO neurons can act as population oscillators. The finding supports models of sensory-motor timing in humans that propose that the IO provides information for monitoring absolute time (Teki et al., 2012; Ashe and Bushara, 2014). Those models are based on the findings of strong $\mathrm{IO}$ activation triggered by deviations in the 
A

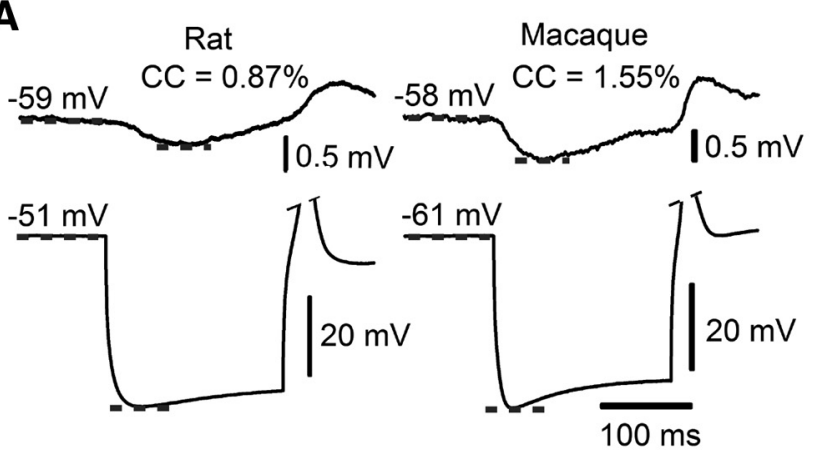

B

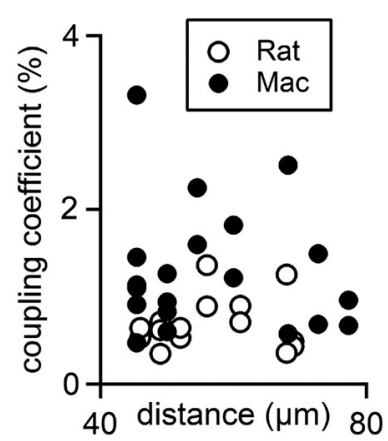

C

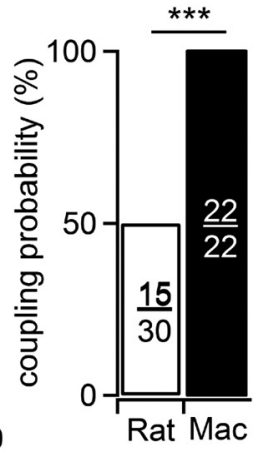

D

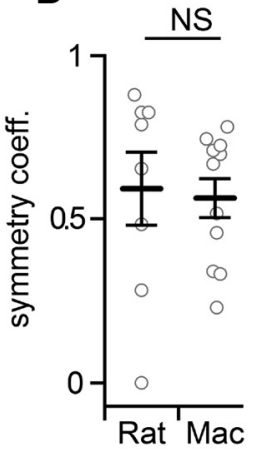

Figure 3. Electrical coupling in macaque $I 0$ is stronger and more prevalent than in rats. $A$, Pre- and post-junctional responses to $-300 \mathrm{pA}$ current injection in rat and macaque I0 neurons. CCS were measured at time/voltage indicated by dashed lines. $\boldsymbol{B}$, Plot of CCs for pairs of 10 neurons spaced $40-80 \mu \mathrm{m}$. Each point is one direction. C, Probability of recording from an electrically coupled 10 pair. N's indicate directions. $D$, Mean symmetry of electrically coupled I0 pairs. ${ }^{* * *} p<0.001$. Error bars show \pm 1 SEM.

A

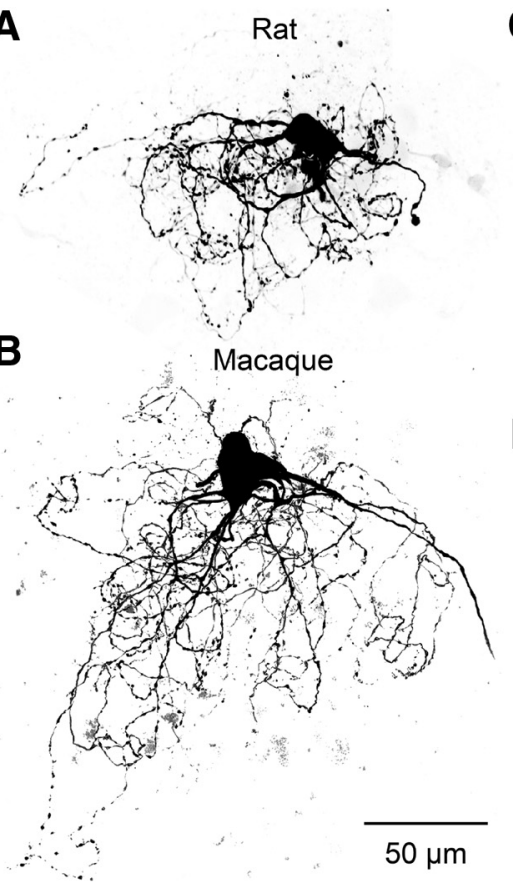

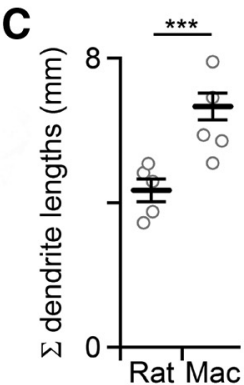

E

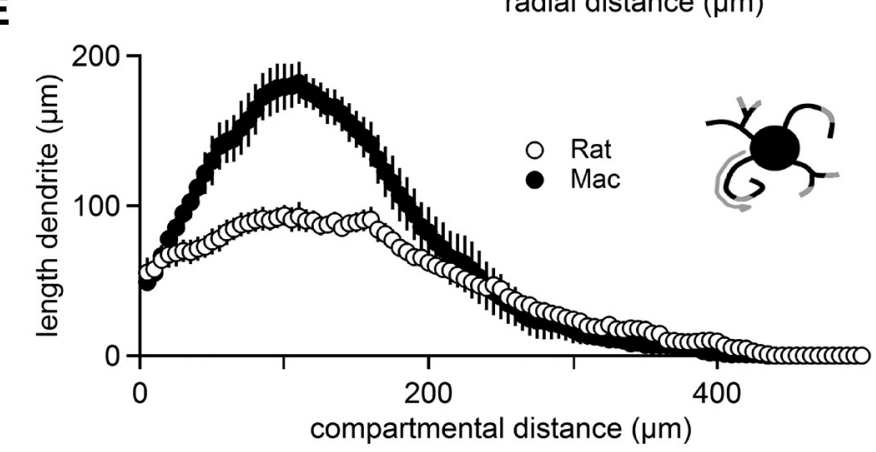

Figure 4. The dendrites of macaque 10 neurons are longer and extend greater distances from the soma than in rats. $\boldsymbol{A}, \mathrm{Z}$-projection of a representative rat 10 neuron. $\boldsymbol{B}$, Same as in $\boldsymbol{A}$, but for macaque. $C$, Average summed length of dendrite per 10 neuron. $\boldsymbol{D}$, Average total length of $\mathrm{IO}$ neuron dendrites at radial distances from the soma. $\boldsymbol{E}$, Average total length of $\mathrm{I} 0$ neuron dendrites at different compartmental distances from the soma $\left(5 \mu \mathrm{m}\right.$ bins). ${ }^{* * *} p<0.001$. Error bars show \pm 1 SEM.

expected timing of sensory events (Teki et al., 2011; Wu et al., 2011). An internal clock-like mechanism could be ideal in tasks requiring discrimination of absolute duration and STOs in the human IO synchronized by strong electrical coupling provide an attractive neurophysiological substrate.

The data presented here provide new challenges toward understanding the role of IO STOs in sensory-motor timing in primates. If timing information is provided by spiking at the peak of the STO, the time resolution of macaque IO neurons would be limited to $250 \mathrm{~ms}$ with the bulk falling into the resolution of 500 ms. Lower frequencies would also be expected to reduce the temporal acuity of IO neurons operating through STO phase coding in which the number of axonal spikelets is determined by STO phase (Mathy et al., 2009; cf. Bazzigaluppi et al., 2012a). One alternative possibility is that more precise temporal information is encoded by phase differences between populations of oscillatory IO neurons (Welsh et al., 1995; Welsh and Llinás, 1997;
Jacobson et al., 2008). In this case, temporal codes in the primate cerebellar cortex would only be evident using large-scale recording of the CF responses of thousands of PCs using methods that have been implemented at small scale in rodents (Welsh et al., 1995; Ozden et al., 2009, De Gruijl et al., 2014).

We have shown that neurons in the primate IO are strongly electrically coupled and demonstrate continuous and synchronized STOs, however, at a slower frequency compared with rats. The findings will inform future experiments and models of sensory-motor timing in primates.

\section{References}

Ashe J, Bushara K (2014) The olivo-cerebellar system as a neural clock. Adv Exp Med Biol 829:155-165. CrossRef Medline

Bazzigaluppi P, De Gruijl JR, van der Giessen RS, Khosrovani S, De Zeeuw CI, de Jeu MT (2012a) Olivary subthreshold oscillations and burst activity revisited. Front Neural Circuits 6:91. Medline

Bazzigaluppi P, Ruigrok T, Saisan P, de Zeeuw CI, De Jeu M (2012b) Prop- 
erties of the nucleo-olivary pathway: an in vivo whole-cell patch clamp study. PLoS One 7:e46360. CrossRef Medline

Chorev E, Yarom Y, Lampl I (2007) Rhythmic episodes of subthreshold membrane potential oscillations in the rat inferior olive nuclei in vivo. J Neurosci 27:5043-5052. CrossRef Medline

De Gruijl JR, Bazzigaluppi P, de Jeu MT, De Zeeuw CI (2012) Climbing fiber burst size and olivary sub-threshold oscillations in a network setting. PLoS Comput Biol 8: e1002814. CrossRef Medline

De Gruijl JR, Hoogland TM, De Zeeuw CI (2014) Behavioral correlates of complex spike synchrony in cerebellar microzones. J Neurosci 34: 8937-8947. CrossRef Medline

Devor A, Yarom Y (2002) Electrotonic coupling in the inferior olivary nucleus revealed by simultaneous double patch recordings. J Neurophysiol 87:3048-3058. Medline

De Zeeuw CI, Chorev E, Devor A, Manor Y, Van Der Giessen RS, De Jeu MT, Hoogenraad CC, Bijman J, Ruigrok TJ, French P, Jaarsma D, Kistler WM, Meier C, Petrasch-Parwez E, Dermietzel R, Sohl G, Gueldenagel M, Willecke K, Yarom Y (2003) Deformation of network connectivity in the inferior olive of connexin 36-deficient mice is compensated by morphological and electrophysiological changes at the single neuron level. J Neurosci 23:4700-4711. Medline

Eccles J, Llinás RR, Sasaki K (1964) Excitation of cerebellar Purkinje cells by climbing fibers. Nature 203:245-246. CrossRef Medline

Hakimian S, Norris SA, Greger B, Keating JG, Anderson CH, Thach WT (2008) Time and frequency characteristics of Purkinje cell complex spikes in the awake monkey performing a nonperiodic task. J Neurophysiol 100:1032-1040. CrossRef Medline

Hoge GJ, Davidson KG, Yasumura T, Castillo PE, Rash JE, Pereda AE (2011) The extent and strength of electrical coupling between inferior olivary neurons is heterogeneous. J Neurophysiol 105:1089-1101. CrossRef Medline

Jacobson GA, Rokni D, Yarom Y (2008) A model of the olivo-cerebellar system as a temporal pattern generator. Trends Neurosci 31:617-625. CrossRef Medline

Keating JG, Thach WT (1995) Nonclock behavior of inferior olive neurons: interspike interval of Purkinje cell complex spike discharge in the awake behaving monkey is random. J Neurophysiol 73:1329-1340. Medline

Khosrovani S, Van Der Giessen RS, De Zeeuw CI, De Jeu MT (2007) In vivo mouse inferior olive neurons exhibit heterogeneous subthreshold oscillations and spiking patterns. Proc Natl Acad Sci U S A 104:15911-15916. CrossRef Medline

Lang EJ, Sugihara I, Llinás R (2006) Olivocerebellar modulation of motor cortex ability to generate vibrissal movements in rat. J Physiol 571: 101-120. CrossRef Medline

Lefler Y, Yarom Y, Uusisaari MY (2014) Cerebellar inhibitory input to the inferior olive decreases electrical coupling and blocks subthreshold oscillations. Neuron 81:1389-1400. CrossRef Medline

Llinás R (1991) The noncontiuous nature of movement execution. In: Motor control: concepts and issues (Humphrey DR, Freund JH, eds), pp 223-242. New York: Wiley.

Llinás R, Yarom Y (1986) Oscillatory properties of guinea-pig inferior olivary neurones and their pharmacological modulation: an in vitro study. J Physiol 376:163-182. CrossRef Medline

Llinás R, Baker R, Sotelo C (1974) Electrotonic coupling between neurons in cat inferior olive. J Neurophysiol 37:560-571. Medline
Longair MH, Baker DA, Armstrong JD (2011) Simple neurite tracer: open source software for reconstruction, visualization and analysis of neuronal processes. Bioinformatics 27:2453-2454. CrossRef Medline

Long MA, Deans MR, Paul DL, Connors BW (2002) Rhythmicity without synchrony in the electrically uncoupled inferior olive. J Neurosci 22: 10898-10905. Medline

Manor Y, Rinzel J, Segev I, Yarom Y (1997) Low-amplitude oscillations in the inferior olive: a model based on electrical coupling of neurons with heterogeneous channel densities. J Neurophysiol 77:2736-2752. Medline

Mathy A, Ho SS, Davie JT, Duguid IC, Clark BA, Häusser M (2009) Encoding of oscillations by axonal bursts in inferior olive neurons. Neuron 62:388-399. CrossRef Medline

Mathy A, Clark BA, Häusser M (2014) Synaptically induced long-term modulation of electrical coupling in the inferior olive. Neuron 81: 1290-1296. CrossRef Medline

Ozden I, Sullivan MR, Lee HM, Wang SS (2009) Reliable coding emerges from coactivation of climbing fibers in microbands of cerebellar Purkinje neurons. J Neurosci 29:10463-10473. CrossRef Medline

Placantonakis DG, Bukovsky AA, Aicher SA, Kiem HP, Welsh JP (2006) Continuous electrical oscillations emerge from a coupled network: a study of the inferior olive using lentiviral knockdown of connexin36. J Neurosci 26:5008-5016. CrossRef Medline

Rutherford JG, Gwyn DG (1980) A light and electron microscopic study of the inferior olivary nucleus of the squirrel monkey, Saimiri sciureus. J Comp Neurol 189:127-155. CrossRef Medline

Sotelo C, Llinás R, Baker R (1974) Structural study of inferior olivary nucleus of the cat: morphological correlates of electrotonic coupling. J Neurophysiol 37:541-559. Medline

Szentágothai J, Rajkovits K (1959) Über den ursprung der kletterfasern des kleinhirns. Anat Embryol (Berl) 121:130-141.

Teki S, Grube M, Kumar S, Griffiths TD (2011) Distinct neural substrates of duration-based and beat-based auditory timing. J Neurosci 31:3805-3812. CrossRef Medline

Teki S, Grube M, Griffiths TD (2012) A unified model of time perception accounts for duration-based and beat-based timing mechanisms. Front Integr Neurosci 5:90. CrossRef Medline

Thach WT Jr (2002) The pacemaker in posthypoxic myoclonus: where and what to do about it? Adv Neurol 89:289-294. Medline

Turecek J, Yuen GS, Han VZ, Zeng XH, Bayer KU, Welsh JP (2014) NMDA receptor activation strengthens weak electrical coupling in mammalian brain. Neuron 81:1375-1388. CrossRef Medline

Welsh JP, Llinás R (1997) Some organizing principles for the control of movement based on olivocerebellar physiology. Prog Brain Res 114: 449-461. CrossRef Medline

Welsh JP, Lang EJ, Suglhara I, Llinás R (1995) Dynamic organization of motor control within the olivocerebellar system. Nature 374:453-457. CrossRef Medline

Welsh JP, Han VZ, Rossi DJ, Mohr C, Odagiri M, Daunais, Grant KA JB (2011) Bidirectional plasticity in the primate inferior olive induced by chronic ethanol intoxication and sustained abstinence. Proc Natl Acad Sci U S A 108:10314-10319. CrossRef Medline

Wu X, Ashe J, Bushara KO (2011) Role of olivocerebellar system in timing without awareness. Proc Natl Acad Sci U S A 108:13818-13822. CrossRef Medline 